\title{
Impact of Human Resource Management Practices on Corporate Entrepreneurship
}

\author{
WAQAR KHAN \\ Business Management Student, University of Haripur \\ M. ATIQ RAFIQUE KHATTAK \\ Lecturer University of Haripur \\ SHAHBAZ AHMED \\ Business Management Student, University of Haripur \\ SHAHZAD KHAN \\ Assistant Professor, University of Haripur
}

\begin{abstract}
This study aims at learning about the Human Resource Management Practices and their effects on Corporate Entrepreneurship (CE). HRM is one of the most crucial departments of all firms as it brings creativity and novelty, in products and services in order to have a competitive edge over rest concerned firms in the market. By properly managing HR an organization can bring this uniqueness. When resources are invested to bring improvement in organizational performance in terms of development in existing products and processes or expansion in product-lines or introducing new idea into practice for economic gain, the process is called corporate entrepreneurship. HRM practices play a vital role in fostering CE. Here, in this study three HRM practices; Training and development $(T \& D)$, Reward and Compensation $(R \& C)$ and Recruitment and Selection $(R \& S)$ are discussed and their impact on corporate entrepreneurship is checked out. This study is based on data that was gathered through questionnaire survey around Industrial estate Hattar (Haipur), PAKISTAN. Results show that there is significant positive relationship between the prescribed human resource management practices and corporate entrepreneurship.
\end{abstract}

Keywords: Corporate Entrepreneurship, T\&D, Reward \& Compensation, $R \& S$.

\section{Introduction}

Businesses now-a-days have to make prompt and frequent changes in their strategies in order to survive amongst tough competitors in the market. Therefore, the think-tanks of every organization must has a keen observation of their strategies, policies, plans and procedures to find and avail each of the single opportunity exists around. Thus at the each single phase of the organization life cycle, firms need to bring novelty in their products and processes, and enhancement in personnel skills to make profitability and sustainable growth. For this purpose actions that drive Corporate Entrepreneurship (CE), provide those organizations with a base of creating and developing those qualities (Zehra et. al., 
2009; Ozdimrici \& Behram, 2014). Therefore, firms are making a continuous incremental investment in corporate entrepreneurship to achieve organizational objectives of profit making and dominating in the market as leading firms. "CE is a process that generates value through compounding together a bunch of resources in order to overwork and pursue opportunities" (Banumathi \& Kumar, 2015). In other words, corporate entrepreneurship is the process of allocating a bunch of resources (Human/intellectual, financial and other physical resources) to identify and avail opportunities that are helpful in bringing novelty (in production and process), improvement (quality and services) and adding value to the organization in terms of profitability and increased market share. Chigamba (2014) stated that, "CE is the chain of integral business activities in the direction of creating a new entry inside or around the existing business."

Human resource management practices (HRM practices) are becoming increasingly vital as rival firms are becoming global day by day (Kaya, 2007). Armstrong (2000) stated Human Resource management (HRM) as "the act of acquiring, motivating and developing human resources." Human resources have a valuable contribution in driving corporate entrepreneurship (Soleimani \& Shahnazari, 2013). Organizations must inspect HR practices to increase its capability of innovation and show more competitiveness (Olughor, 2014). Therefore in order to foster CE, human resource management practices have a vital role.

"CE always takes place by having a very clearer stand of administration regarding power decentralization, contribution while making decision, joint cooperation, averting bureaucracy, promoting risk taking and creativity (Luchsinger \& Bagby, 1987)." High performance human resource practices systems are effectual to the degree that these have positive impact on employees and urge them to participate to vital organizational outcomes (Mustafa et. al., 2013). Previous literature thus depicts that all human resources management practices plays vital persona in fostering CE. But here in this study three various HRM antecedents are discussed in literature and their impact on CE is judged. These HRM antecedents are; Training and development (T\&D), Reward and Compensation $(\mathrm{R} \& \mathrm{C})$ and Recruitment\& Selection $(\mathrm{R} \& \mathrm{~S})$.

This is a vital stride in the quest for effectiveness and execution in an outcome of poor enlistment is colossal and can be most likely deadly to the organization. Martory and Crozet confirm that the demarche of enrollment is crucial part of the HR arrangement of the organization; it might actually impact the bearings totally as opposed to the condition of human potential one. For corporate advancement regarding CE, the goal of staff determination is to frame a fitting asset base of human money to cultivate entrepreneurial action in the setup of organization.

$\mathrm{CE}$ was not fair from a high ground perspective. Corporate business visionaries are in a conventional position to get an immense offer of the rents they add to make and they are especially flexible resources whose exit plan can hurt the association's human and social capital. In order to control what we have called the liabilities of individualization, boss need to arrange and realize adequate upkeep instruments. Various managers acknowledge that the issue of upkeep is reducible to an issue of compensation and that if gainful individuals are proposed engaging pay rates and pay-based driving forces they won't get out. Sadly, this supposition is false on a couple records (Cappelli, 2000). 
Planning and progression practices can raise entrepreneurial behavior to the extent that they apply to an extent of occupation circumstances and engage specialist speculation (Schuler, 1986). Changing occupation demands and always showing signs of change advancements suggest a necessity for setting up that is nonstop, is less organized and spotlights on individual learning prerequisites (Campbell, 2105). This is why T\&D is one of most essential HRM practice to foster out CE.

Researchers in the past have studied the impact of the above mentioned HRM antecedents on CE separately in various studies which shows a positive relationship between all these practices and CE. But no one in the past has collectively studied the impact of these HRM practices $(R \& S, T \& D$ and $R \& C)$ over corporate entrepreneurship. This study, therefore strives to fill this research gap.

\subsection{Problem Statement}

Since last three decades, a little but growing study has egress which analyzes the affiliation between HRM practices and corporate entrepreneurship in an empirical manner. Despite, an important challenge is still there for investigators in making a conclusion from the previous study as $\mathrm{CE}$ is not a single dimensional construct (Hayton, 2005). Therefore, the study of HRM practices' impact on CE is still a debatable area for researchers, as no researcher in the past collectively studied the impact of these particular HRM practices $(R \& S, T \& D, R \& C)$ on CE. Specially, in Pakistan there is no study done before, regarding this topic.

\subsection{Purpose of the Study}

This study carries three multiple purposes which are as following;

- To find out the relationship between HRM practices and corporate entrepreneurship (CE),

- To analyze the impact of HRM practices on CE and;

- To make distinguish between these specific HRM practices based on the importance having for the CE.

\subsection{Research Questions}

This study is primarily based on three questions which are;

- What is the impact of multiple HRM practices on CE?

- Do HRM practices significantly matter in promoting CE?

- How much importance does HRM practices held in the promotion of CE?

2. Literature Review

\subsection{Corporate Entrepreneurship (CE)}

The term Corporate Entrepreneurship (CE) is used to depict entrepreneurial behavior within an already established medium or large organization (Botha and Nyanjom, 2011). During the 18th century the two economists Jean-Baptist and Joseph Schumpters have presented the concept of corporate entrepreneurship which is derived from French language that means "to combine the resources for profit making". CE is a process of generating value through compounding collectively a bunch of multiple resources to overwork and pursue opportunities (Banumathi \& Kumar, 2015). Thus CE is the process of allocating a bunch of resources to identify and avail opportunities that are helpful in bringing novelty, improvement and adding value to the organization.

In the past two decades, the concentration of literature in the area of corporate entrepreneurship has changed enormously (Kahkha, 2014). Entrepreneurial or innovative 
functions nourish already established companies, without regard to their scale and type of production (Otache \& Mahmood, 2015) therefore each organization can promote CE. Corporate entrepreneurship is the chain of integral business activities in the direction of creating a new entry inside or around the existing business (Chigamba, 2014). Entrepreneurs carry out their creative ideas into the firm to develop corporate entrepreneurship (Shah \& Bhutta, 2013) and add values to the organization.

The term CE has been discussed since a few decades, the definition of CE is away from making the unanimity of the researchers (Maalej, 2014) because corporate entrepreneurship has been defined by multiple researchers in various ways. Like, "The process of striving to develop a new organization or to bring novelty by an individual or group in an already established company is called CE (Sharma \& Chrisman (1999)." According to Sathe (1989), Corporate Entrepreneurship refers to "organizational renewal." It prolongs regeneration by improving process and removing faults in a product or service, environment redefinition, company redefinition and business model innovation (Kuratko \& Audretsch 2013), and certain processes such as corporate execution (Brettel, et. al., 2012).

$\mathrm{CE}$ is either a combination of formal or informal actions which proceed towards generating new businesses in existing companies by bringing innovation in production and process, and developing position in the market (Zahra, 1991). Such actions might be seen at the corporate, division (business), functional, or project levels, with the amalgamating purpose of making improvement in an organization "s competitive state and financial performance (Maalej, 2014). CE also implicates the strategic renewal of an established company. It is an attempt to unify both skills and mentality of successful entrepreneurs and instill these features into the cultures and actions of a big firm (Thornberry 2002). CE is a wide concept that comprises of generation, improvement, and execution of new business ideas or behaviors.

In general sense, CE comprises of the activities involved in the improvement of newer business ideas and opportunities within big and already developed firms (Birkensha, 2003). (Ierland, Kuratko \& Morris, 2006) presented CE as a process through which individuals in an already formed company find and avail entrepreneurial opportunities to innovate without regard for the level and kind of existing resources. The nature of corporate entrepreneurship is "heterogeneous" (Phan et. al., 2009). However, with the elevations of studies regarding corporate entrepreneurship during the last decade, a more clear view on CE has emerged (Kuratko \& Audretsch, 2013).

$\mathrm{CE}$ is a pro-founding activity practiced by firms for gettingsurvival in the long run; it leads to superior performance and it might seem as a source of advancing and prolonging a firm "s series of short run competitiveness which could be resulted in sustainable competitive edge. The constructs of CE comprises of; Employee Autonomy, Innovativeness or (Creativeness), Proactiveness, Competitive Aggressiveness, and Risktaking (Chigamba et. al., 2014).

Employee Autonomy is a state where individuals or group individuals of are provided with liberty in order to have initiatives in searching and overworking recognized opportunities without being impeded by bureaucratic processes (Otache \& Mahmood, 2015). It is the extent of freedom to which an employee brings and develops his idea, the degree of risk taking and the degree of which an employee's participation in making 
decisions along with concerned management. Innovativeness is the debut of new way of production, processing, or doing some strategic betterment to the current products and processes (Otache \& Mahmood, 2015). Innovativeness or creativeness is the capability of either bringing novelty in an existing product or process or creating a product or introducing a process that does not exist before. Product innovativeness is the process of launching a unique product or importantly meliorated with respect to its features or destined uses (Atalay, Anafarta \& Sarvan 2013). Process innovation is the execution of a unique or significantly meliorated production or method of delivery (Trott 2010). Innovativeness is the process of launching unique products, processes, or making some strategic developments to current products or processes. The higher the employee $s$ innovative environment will be the positive effects for CE there will be (Farrukh et. al., 2014). Therefore, organizations should critically focus on innovative environment.

Pro-activeness is opportunity-searching, forward-looking perspective involved in acquainting unique products and services in competitive markets and involvement in the prediction of upcoming demand to bring change and form the environment (Banumathi \& Kumar, 2015). It is a state where a firm forestalls opportunities and manages resources for the development of the recognized opportunities before the competitors discover the existence of such opportunities (Otache \& Mahmood, 2015).

Competitive Aggressiveness/ Need for Achievement is the desire of a firm to exceed competitors by altering, its competitive strategies policies or proficiencies that are bent in the ways resources are used (Otache \& Mahmood, 2015). It is the set of bold decision and implication of newer and improved strategies that are undertaken by a firm to have competitive advantages over its rivals in the market. It carries people, specially, entrepreneurs, who tend to perform in such manners that make them to accomplish the entrepreneurial and leadership role in a successful manner (Fynn, 2005).

Risk-taking refers to cheerful compliance to pull possessive resources or to adopt resources for a venture or a project regardless having certainty of making gain (Otache \& Mahmood, 2015). In other words it means to allocate asset/resources to projects where the outcomes are uncertain (Karacaoglu et. al., 2013). Thus, CE is a multi-dimensional construct (Zehir et. al., 2012) and most often these constructs are interdependent on each other.

Beside the above components of CE, Botha and Nyanjom, (2011) proposed another component that drives CE which is called 'Focused Knowledge.' "Knowledge is a mixture of information, experiences and insights that offer a model which may be executed in a thoughtful manner while evaluating new information or assessing specific situations (Zikmund, 2003)." Thus, it can be firmly said that focused knowledge is plays a vital role in fostering CE environment within and outside the organization. $\mathrm{CE}$ is thus, seen as a mixture of 3 core elements: the creator, the creating process and the new value creation (Maes, 2004). The creating process (element 1) is the course of actions which are undertaken by the firm to follow entrepreneurial opportunities. It implicates a number of steps, like finding and identifying new business opportunities, searching information and the acquisition and accretion of resources (Shane \& Venkataraman, 2000; Ucbasaran et al., 2001). CE intends at creating new value for the firm (Element 2). New value may be generated by introducing unique products (innovation), services or processes by taking initiatives and entering into new markets (venturing) and by redefining the business 
concept (strategic renewal) (Antoncic \& Hisrich, 2001; Lumpkin \& Dess, 2001; Zahra \& Covin, 1995).The creator; (component 3) runs the creating process. Creator is an individual or group that launches a new idea, product or service that adds values to organization market value. Creator is basically invention oriented.

There are two phenomenons that establish the state of CE; corporate venturing and Strategic entrepreneurship (Morris et al., 2008). Corporate venturing is formation of new businesses inside the existing firm. Strategic entrepreneurship is the exhibition of masslevel or highly important innovations that are made inside the company to avail competitive edge (Kuratko, 2009). These innovations may or may not turn into further businesses for the organization. Thus, CE is the process of allocating a bunch of resources to identify and avail opportunities that are helpful in bringing novelty, improvement and adding value to the organization.

\subsection{Human Resource Management (HRM) Antecedents and CE}

Human Resource management (HRM) is defined by Armstrong (2000) as "the acquisition, motivation and development of human resources." „Acquisition" is the process attracting and selecting potential recruits for a specific job. „Motivation "e means to push someone to insert more effort for achieving organizational goal as well as personal satisfaction. „Development ${ }^{\text {ec }}$ refers to prepare employees to perform certain jobs in their future career, to be more concise, employees are provided with development in order to keep retain the potential employees. HRM practices have been widely studied by researchers in recent past and declared effective in pushing variety of performance indicators in organizations (Keld \& Foss, 2003). HR practices may have a valuable impact on reinforcing CE (Soleimani \& Shahnazari, 2013). However, only a few researchers of them have judged the impact of HR practices on an organizations overall $\mathrm{CE}$ and explicated how human resource practices straightly effect CE (Zhang et al., 2008).

HRM is one of the most fundamental disciplines of making managerial decisions which affect CE (Kuratko et. al., 2005; Schuler, 1986).Thus organizations are highly dependent on HR departments because most of the managerial decisions are passed from here which may result in success or failure. Human resources management practices (HRMPs) as components regulating human and social capital are very much important to promote and ease corporate entrepreneurship (Ozdimrici and Behram, 2014) therefore the high performance HRM practices are helpful in promoting CE. HRMPs are the central elements that contribute to make a firm enable to become proactive, creative and able to take risk (Fong et.al, 2013). Human resource programs linked with recruitment, selection and training programs are designed to guarantee that employees have the features needed for effective development of CE (Morris et. al., 2006).

Chandler et al. (2000) stated that HRM has an important impact on creativity and innovation as by creating a supportive culture. HRMPs like compensation, performance evaluation, working teams, segregation of tasks and duties, top management support for innovation, employment, job designing and education were regarded in that survey as effective HR practices on CE (Soleimani \& Shahnazari, 2013). Therefore, all the HR policies are very much valuable in order to create a supportive culture for CE. HRM as a system of management activities aims to stimulate modification in the employee base toward CE (schmelter et. al., 2010). 
It is thus informative that an effective HRM policy on recruitment of employees, who are most responsible for creating business value and generating competitive advantage, is essential for the firm's success. HRM practices which are discussed in this study ahead are; $R \& S, T \& D$ and $R \& C$. These HRM practices have a significant positive relationship with $C E$ as per past studies.

\subsection{Recruitment and Selection $(\mathrm{R} \& S)$}

A fruitful development process requires exceedingly qualified individuals to be included (Brazeal, 1993; Hayton, 2005). For corporate development regarding CE, the goal of staff determination is to shape a proper asset base of human cash-flow to encourage entrepreneurial movement in the set up SME. Amid the determination process, organizations can decide the critical thinking and cooperation states of mind and practices of planned workers. We along these lines accept specific enlisting is an essential device organizations can use to impact their CE level. Past HRM research results have proposed that organizations that utilize staff with master learning and a few entrepreneurial capacities, for example, innovativeness and proactiveness, can respond immediately when unforeseen open doors or changes happen (Kaya, 2006).

In this manner, when all is said in done, the choice criteria ought to be in accordance with the CE measurements of creativity, danger penchant, genius animation, corporate wandering, and self-restoration (Roberts, 1977; Saly, 2001). What's more, it is critical to augment this asset base persistently after some time (Morris \&Jones 1993) to maintain a strategic distance from the visual deficiency that outcomes from directing routine techniques (Sathe, 1989). The estimation things associate the build of staff choice and CE. Our investigation uncovered four perspectives that ought to be incorporated into this develop. In the first place, new administration staff ought to have pertinent KSAOs, which means the staff is imaginative or has a pizzazz for activity (Schuler, 1986). Second, in accordance with Sathe (1989).

We foresee that new outer workers will be essential for new thoughts, accordingly making more elevated amounts of CE. Third, approaches to progress in one's own vocation way ought to be complex. This perspective spurs representatives to take after whimsical thoughts or go for broke. It can prompt both higher CE power and an individual improvement inside of the organization. Fourth, aptitudes, for example, the abilityto work in a group are imperative for $\mathrm{CE}$, as entrepreneurial exercises are normally group arranged.

In the HRM framework, particular enlisting has an imperative spot. Amid the determination process, firms ought to discover which states of mind and practices representatives have toward critical thinking and group working. Furthermore, firms need to draw in apt workers and adjust them to the company's qualities and objectives. These apt representatives ought to be kept longer in the firm. Also, the supply of capable and talented representatives to firms might serve to improve entrepreneurial understanding. Fruitful enlisting hone gives firms workers who can start and settle on proper choices.

As indicated by HRM writing, all organizations, however little, do have any significant bearing HRM hones, despite the fact that this capacity can be certain (Aldrich and Von Glinow, 1991). Be that as it may, enlistment is by all accounts a standout amongst the most difficult HRM assignments for little organizations. This is because of their absence of money related and material assets (Hannan and Freeman, 1977) and, in rising firms, 
the absence of experience. In such firms HRM frequently turns into the obligation of the general administrator, as opposed to of prepared HRM experts (Longenecker, Moore and Petty, 1994). Under these circumstances drawing in and selecting skillful personnel can turn into an issue (Arthur, 1995). Barney (1991) sets that numerous organizations, rather than agony the risk of novelty, transform their state of development into an upper hand. Their procuring practices would leave from the business standards; cases would incorporate the nonattendance of sets of responsibilities (or having just ambiguous ones) or the nonappearance of stock-based remuneration (Alexander,1999). Quickly developing firms are regularly established with being "hostile to bureaucratic", and their way to deal with providing so as to employ is portrayed sensible sets of responsibilities, conveying both positive and negative parts of a vocation (Deshpande \& Golnar, 1994).

The powerlessness to anticipate how and if a given individual will fit inside of the following level of firm development can in this manner turns into a noteworthy issue for the authors, similarly as enlistment is concerned. Enrolling center workers through informal organizations amid the start-up stage might improve this issue. Enrollment and determination is the procedure by which representatives are distinguished and set in an association to guarantee that objectives and targets are met. Be that as it may, the procedure of enrolling and selecting staff is fairly distinctive for SMEs. Some of them don't have clear strategies and methods, in that capacity enrollment and choice is regularly along family lines or referrals. This regularly impedes imagination on occasion as there is a likelihood that a few aptitudes perhaps in overabundance supply inside of the SMEs. The little business area is generally hesitant to allot consumption on preparing and improvement. Enlistment and choice of staff is additionally a noteworthy test as some entrepreneurs get to be wary about enrolling outcasts to join their organizations (Kowang et al, 2014).

\subsection{Training and Development (T\&D)}

Preparing and advancement (Amabile, 1988; Khandwalla, 2006). When all is said in done, preparing and change are essential for the affiliation's execution (Alders et al, 2002) and high ground (Garcia-Falcon et al, 2002). Besides, can vanquish the variables that diminishing specialists' livelihood execution and satisfaction (Xiao, 1996).( Becker2003)characterized staff progression as activities that assemble delegates' capacities and execution at all different leveled levels through preparing, calling organization, and work structure. Planning and progression practices can raise entrepreneurial behavior to the extent that they apply to an extent of occupation circumstances and engage specialist speculation (Schuler, 1986). Changing occupation demands and always showing signs of change advancements suggest a necessity for setting up that is nonstop, is less organized and spotlights on individual learning prerequisites (Campbell, Dunnette, Lawler, \&Weick, 1970; Hambrick and Crozier, 1985; Kuratko, Mon agno, and Hornsby, 1990; Schafer and Graham, 2002).

This arrangement approach enables specialists to respond in phenomenal ways to deal with new troubles, conform to dynamic natural conditions, and feel extraordinary with unclearness. It furthermore bolsters inventiveness by enabling agents to build complex experiences (Amabile, 1988; McGinnis \&Ackelsberg, 1983). For fruitful planning, ventures should fit the association's procedure and work process. To unwind their full effect on CE, ace data, social ability, imagination, and conscious inclination are 
especially basic to be seen as (Khandwalla, 2006; Morris and Jones, 1993). Preparing is a fundamental part of the engine and the HRM is an impulse for human change of the association. It intends to make HR through retribution and satisfaction of get ready needs (doh 2006). It grows their Singular breaking points and advances their change. In like manner, the planning keeps up the wellness and suitability of HR by the sufficiency work/position. At the point when all is said in done, get ready and progression are essential for the affiliation's execution (Alders, et al 2002) and high ground ( GarciaFalcon et al, 2002). Likewise, planning can overcome the variables that decrease agents' occupation execution and satisfaction (Xiao, 1996). Berthel and Becker (2003) described staff improvement as activities that grow laborers' capacities and execution at all dynamic levels through preparing, calling organization, and work structure. Planning and headway practices can hoist entrepreneurial behavior to the extent that they apply to an extent of occupation circumstances and invigorate delegate speculation (Schuler, 1986).and shaw, E,(2005), corporate business enterprise and advancement area 1; the missing association, European journal of improvement administration.

\subsection{Reward and Compensation ( $R \& C)$}

$\mathrm{CE}$ was not fair from a high ground perspective. Corporate business visionaries are in a conventional position to get an immense offer of the rents they add to make and they are especially flexible resources whose exit plan can hurt the association's human and social capital. In order to control what we have called the liabilities of individualization, boss need to arrange and realize adequate upkeep instruments. Various managers acknowledge that the issue of upkeep is reducible to an issue of compensation and that if gainful individuals are proposed engaging pay rates and pay-based driving forces they won't get out. Sadly, this supposition is false on a couple records (Cappelli, 2000).

To begin with, investigation has set up that people involved with CE for money related and non-fiscal points of view, for instance, the necessity for achievement and business satisfaction and that in sweeping associations, the non-financial expectations ruled (von Hippel, 1977). Second, pay based support instruments are easily planned by battling affiliations developed associations or venture saves (Cappelli, 2000). Remembering the deciding objective to hold critical individuals, enterprises convey to the table more than charming cash related prizes. What sorts of prizes will work? There are no fundamental responses to this inquiry, since each corporate business visionary has particular motivations and longings.

With a particular final objective to hold corporate businessmen, managers should probably know not motivations and seeks and propose revamp prizes and forces (Cappelli, 2000). Specialists' satisfaction and segments related to it are fundamental components for organization, various leveled behavior and progression of the affiliation (Lofquist \& Dawis, 1969; Smith et al., 1969; Locke, 1976; Cranny et al., 1992). Agents' satisfaction exhibits interest level of laborers to their job (Specter, 1997). It is exhibited that hypothesis on agents could fortify their own particular creative ability (Homet al., 2009) that is crucial for corporate business enterprise. Regard and fantastic obligation of delegates could strengthen improvement in the affiliation (Kanter, 1984). Basic variables of occupation satisfaction in the present diagram consolidate total satisfaction of agents from work, laborers' relations (Mayer, 1991; Miskell and Miskell, 1994; Welsby, 2003) and delegates' steadfastness (Tsuiet et al., 1997; Varona, 2002) 
As for, target staff reports have communicated that acceptable helpers can fabricate laborers' peril liking and motivation for progression (Amabile, 1988; Huselid, 1995). Rousing strengths are both budgetary and non-cash related prizes consequently for the delegate's work execution (Morris \&Kuratko, 2002). In this present study's setting, we are especially captivated by the delegate's entrepreneurial execution regarding the five CE estimations. Suitable prizes develop an execution evaluation that considers entrepreneurial development. Subsequently, the staff appraisal should fuse unequivocal measures of innovativeness and peril partiality. This construes using subjective and subjective measures of execution despite quantitative execution measures (Lumpkin, 1989; Sathe, 1988). Properly, execution examinations ought to highlight results as wellas considerations and techniques used to finish those results (Kuratko et al., 1990; ; Schuler et al, 1986; Waterman, 1987). Past studies have not agreed on the most ideal approach to blueprint staff rewards, in light of the fact that budgetary and nonfinancial prizes impact tricky influence enabling entrepreneurial presentation (Balkin\& Logan, 1988; Saly, 2001). To a restricted degree, these prizes are as per and even supplement each other (Sathe, 1989) yet might even be counterproductive (Amabile, 1988; Saly, 2001).

Considers have agreed, in any case, that staff rewards must be surrounded adaptably remembering the final objective to react to momentous circumstances (Morris and Jones, 1993; Sykes, 1992) and innovative circumstances (Quinn, 1985). Besides, few studies have contemplated that budgetary prizes must be measurable remembering the deciding objective to incentivize entrepreneurial delegates to stay with the association (Peters,1991;Pinchot,1985). Along these lines, this speculation reinforces sorts of pay related to execution, disregarding that human behavior is not for the most part ordinary and the man does not work only for cash. Close by with enrolment, compensation is another basic locale for little firms' survival and advancement. Suitable compensation is basic for creating firms to secure focus blessings (Stevens, 2004). Entrepreneurial firms are willing to repay creativity, progression, preparation to put it all out there, cooperation, astute behavior and versatility for ambiguity and powerlessness (Logan, 1988). Rewards systems are regularly considering rewards which may fuse both advantage and stock sharing (Stevens, 2004). By making the estimation proprietorship eagerness for the firm, such systems grant rising firms to hold focus blessings (Barringer et al., 2005; Stevens, 2004).

Nevertheless, as showed by Barringer's et al. (2005) examination of rapidly creating firms - asserted gazelles - giving the specialists money related driving forces and venture opportunities is an unmistakable component of gazelles stood out from their progressively creating accomplices. Also, giving the staff inconspicuous pay rates and liberal prizes if the firm performs well, allows rapidly creating firms to move a touch of business risk to the agents (Barringer et al., 2005). Firms cash related prizes are not normal for a delegate's status, as traditional different leveled refinements are kept to a base ( Logan, 1988). Or maybe, entrepreneurial firms give a multidimensional prize considering the outcome from acting in vague circumstances, which joins wagering on improvements. The satisfaction and commitment of having a stake in the business implies the clear slants of prize (Graham et al., 2002). Furthermore, rapidly creating firms consistently work without formal HR approaches for pay, which is as often as possible masterminded on an individual reason dependent upon the necessities and resource 
restrictions of the firm and, on the other hand, on the aptitudes and experience of the delegates (Balkin \& Swift, 2006). Barringer et al., (2005). Pay suggests the distinctive systems by which delegates are compensated for their dedication to the affiliation. These distinctive sorts of prizes as often as possible fuse cash related such wages and nonmoney related compensates, for instance, helpful aide. Regardless of the way that pay is charming SMEs frequently don't have the cash related resources required to hold fit specialists (Long et al., 2014). Lion's offer of the South African masses have not been related to wind up representatives in that limit they need to enter the occupation market as sought after specialists in light of current circumstances this makes challenges similarly as paying according to business segment rates. Rogerson, (2009). Compensation has been impacted by contracting markets as, in various studies, it is found that inspiring powers have influences on firm execution (Bae et al., 2003). A general objective of catalysts is to change manners and convince agents. Forces that upgrade positive perspective and representatives can add to affiliation's improvement. This advancement can be shown through animating delegates to fulfill higher business results. In studies that participate in HRM sharpens with CE, Hayton, (2005) assessed that the HR routine of compensation effect on improvement, has gotten the most thought.

\subsection{Hypotheses}

- H1: There is significant and positive relationship between staff selection and corporate entrepreneurship.

- H2: There is significant positive relationship between staff reward and corporate entrepreneurship.

- H3: There is significant positive relationship between staff training and development and corporate entrepreneurship.

\subsection{Theoretical Framework Dependent variable}
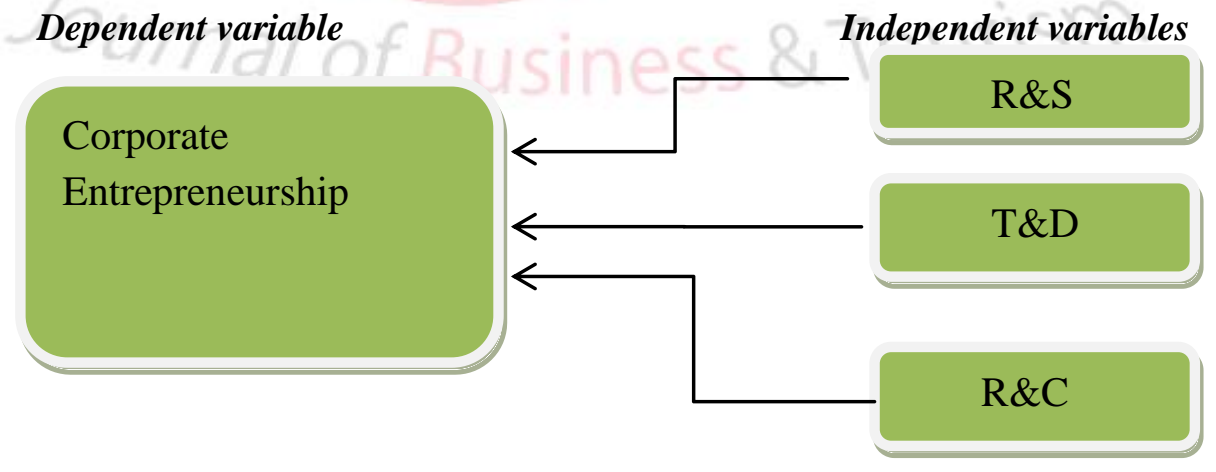

\section{Methodology}

In this study we investigated the proposed relationship between HRM practices and corporate entrepreneurship. This study has discovered the survey designed to investigate whether independent variables such as staff selection, Training \&Development and reward promote the dependent variable corporate entrepreneurship activities in the industrial area Hattar, Haripur. This study is based on targeted population of 20 factories of industrial area Hattar, Haripur. Data collection source was primary. Data were collected through using structured questionnaire administered to middle level management staff of the sampled company. A total of 120 questionnaires were 
distributed, out of them 81 respondents were found usable for the study. The data in this study is undergone and analyzed through SPSS version 20.0, which is normally used for analysis of the researches. Following tools have been utilized for the analysis;

\section{Table 1: Correlation Analysis}

\begin{tabular}{llllll}
\hline & & SS & TD & RC & CE \\
\hline \multirow{3}{*}{ SS } & Pearson Correlation & 1 & & \\
& Sig. (2-tailed) & & & \\
& N & 81 & & \\
& Pearson Correlation & $.555^{* *}$ & 1 & & \\
TD & Sig. (2-tailed) & .000 & & & \\
& N & 81 & 81 & & \\
& Pearson Correlation & $.653^{* *}$ & $.602^{* *}$ & 1 & \\
RC & Sig. (2-tailed) & .000 & .000 & & \\
& N & 81 & 81 & 81 & \\
& Pearson Correlation & $.649^{* *}$ & $.472^{* *}$ & $.629^{* *}$ & 1 \\
CE & Sig. (2-tailed) & .000 & .000 & .000 & \\
& N & 81 & 81 & 81 & 81 \\
\hline
\end{tabular}

**. Correlation is significant at the 0.01 level (2-tailed).

The mean value of staff selection is 4.1.The minimum value of staff selection is 2.83 , The maximum value of staff selection is 4.83 , The standard deviation of staff selection is 0.58 , The total number of respondent are 81.the minimum value of T\&D are 2.86 , The maximum value of $T \& D$ are 4.86.The mean value of $T \& D$ are 4.01 , The standard deviation of T\&D are 63141 , The minimum value of reward or compensation 2.50 , and maximum 5.00, mean value 3.98, the value of standard deviation .6787, The minimum value of Corporate entrepreneurship are 3.0, maximum value are 4.92, mean value are 4.15, and the standard deviation are .5326.

Explanation: There is positive and significant correlation between training and development and staff selection. The value of correlation are .555 .similarly the relationship between staff selection and reward or compensation, values are(.653).And the relationship between staff selection and corporate entrepreneurship positive and significant. The values are (.649). the relationship between training \&development and reward are significant and positive and the values are (.602). the result of $\mathrm{T} \& \mathrm{D}$ and $\mathrm{CE}$ are positive and significant(.472). The result of reward and corporate entrepreneurship are positive and significant the values of these variable are (.629). Dependent Variable: CE the slope staff selection is .368, that is positive and the value of alpha is .001. that shows there is positive and significant relationship. The value of training and development is.037 which shows positive and the value of alpha is .679 that shows insignificant relationship. Reward value is.266 which is positive and the value of alpha is .004 which shows significant relationship. 


\section{Conclusion}

The results show that HRM practices play a significant role in fostering and maintaining high levels of CE. SMEs seeking to induce entrepreneurial activity should focus on the HRM practices of staff selection, staff development and training, and staff rewards that align employee motivation and entrepreneurial firm development. Carefully selecting and designing HRM practices are essential for encouraging CE and, thereby, creating competitive advantage. Therefore, we should carefully employ our staff, give them with proper training and development opportunities and pay them with adequate rewards. So that $\mathrm{CE}$ culture could be developed in order to survive in existing markets.

\section{References}

Ahmad, S., Khattak, A., \& Siddiqui A. (2106). Impact of Human Resource Management Antecedents on Corporate Entrepreneurship. University of Haripur Journal of Management (UOHJM) Published by University of Haripur. Vol.01 www.uoh.edu.pk/uohjm

Ahmad, N.H., Nasurdin, A.M., \& Zainal, S.R.M., (2012). Nurturing Intrapreneurship to Enhance Job Performance: The Role of Pro-Intrapreneurship Organizational Architecture. Journal of InnovationManagement in Small \& Medium Enterprises, Vol. 2012, Article ID 868880, 9 pages. http://www.ibimapublishing.com/journals/JIMSME/jimsme.html

Antoncic, B. \& Hisrich, R.D. (2001). Intrapreneurship: construct refinement and crosscultural validation. Journal of Business Venturing, 16: 495-527.

Atalay, M., Anafarta, N., \& Sarvan, F. (2013). The Relationship Between Innovation and Firm Performance: An Empirical Evidence from Turkish Automotive Supplier Industry. Proceedings- Social and Behavioural Sciences 75, 226- 235.

Bagul, D. B. (2014). A research paper on Study of employees performance appraisal system. Scholarly research journal for humanity science and English language. FEB-MARCH, . Vol. -I, ISUE-II. 287-292.

Banumathi, M., \& Samudhara raja kumar, C. (2015). Influence of high performance work system, emotional intelligence and entrepreneurial orientation on corporate entrepreneurship. International Journal of Recent Scientific Research. Vol. 6(9), pp.6105-6110, September, 2015. http://www.recentscientific.com

Botha, M., \& Nyanjom, M. D. O., (2011). Corporate entrepreneurship orientation and the pursuit of innovating opportunities in Botswana. Acta Commercii 2011. Pg 45.

Chandler, G.N., C. Keller and D.W. Lyon, (2000). Unraveling the determinants and consequences of an innovation supportive culture. Entrepren. Theory Pract., 25(1): 59-76.

Chigamba, C., Rungani, E.C., and Mudenda, C., (2014). The Determinants of Corporate Entrepreneurship for Firms in Adventure Tourism Sector in South Africa. Mediterranean Journal of Social Sciences, Vol. 5(9), Doi:10.5901/mjss.2014.v5n9p713

Farrukh, M., Iqbal, S., Tanzila., \& Khan, I. (2014). The Impact of Innovation Climate \& Job Satisfaction on Corporate Entrepreneurship. Journal of Asian Business Strategy. 4(12), 208-216. http://aessweb.com/journal-detail.php?id=5006 
Fong, Y.C., Ng, K.Y., Tan, S.P., \& Seow, A., (2013). Does Leadership and HRM Matter on Corporate Entrepreneurship? Human Resource Management Research, 3(1), 7-10.

Fynn, C. A., (2005). A founders strategy and entrepreneurial leadership are critical elements in growing and developing a midsized venture. DPhil (Entrepreneurship) thesis, Department of Business Management, University of Pretoria, South Africa.

Grote, D. (2002). The Performance Appraisal, Question And Answer Book A Survival Guide for Managers. AMACOM, USA.

Hayton, J. C. (2005). Promoting corporate entrepreneurship through human resource management practices: A review of empirical research. Human Resource Management Review, 15, 21-41.

Hornsby, J.S., Naffziger, D.W., Montagno, R.V., \& Kuratko, D.F., (1993). Implementing entrepreneurial thinking in established organizations, Advanced Management Journal, 58 (1), 28-33 (Winter).

Kanter, R. M. (1984). The change masters. New York: Touchstone / Simon \& Schuster.

Keat, K. E., (2012). Corporate entrepreneurship and employees' work performance: the impact of individual and organizational factors.

Khan, H. M. A., Chandio, J. H., \& Farooqi, M. T. K., (2014). Comparison of Performance Appraisal System in Public and Private Schools. Pakistan Journal of Commerce and Social Sciences 2014, Vol. 8 (1), 272-278.

Kuratko, D. F. (2009). The entrepreneurial imperative of the 21st century. Business Horizons, BUSHOR- 758. www.elsevier.com/locate/bushor

Kuratko, D. F. \& Audretsch, D. B. (2013). Clarifying the domains of corporate entrepreneurship. International Entrepreneurship Management Journal, Vol. 9, pp. 323-335. DOI:10.1007/s11365- 0130257-4

Kuratko, D. F., Hornsby, J. S. \& Covin, J. G. (2014). Diagnosing a firm "s internal environment for corporate entrepreneurship. Business Horizons, Vol. 57, pp. 3747.

Lerner, J. \& Malmendier, U. (2007). With a Little Help from My (Random) Friends: Success and Failure in Post-Business School Entrepreneurship Working Paper.

Maalej, R., Amami, I., \& Saadaoui, S. (2014). Linking Corporate Entrepreneurship with Human Resources Management Practices. International Journal of Science and Research (IJSR) ISSN (Online): 2319-7064

Maes, J. (2004). The search for corporate entrepreneurship: a clarification of the concept and its measures. DTEW Research Report 0429.

Mead, S., Hilton, D., \& Curtis, L. (2001). Psychiatric Rehabilitation Journal, 25(2), 134 141.

Morris, M. H., \& Kuratko, D. F. (2002). Corporate entrepreneurship - entrepreneurial development within organizations. Fort Worth, Texas: Harcourt, Inc.

Morris, M. H., Kuratko, D. F., \& Covin, J. G. (2008). Corporate entrepreneurship \& innovation. Mason, $\mathrm{OH}$ : Cengage/SouthWestern Publishers.

Nandra, R. \& Sorenson, B. J. (2010). Workplace Peers and Entrepreneurship. Harvard Business School. Working Paper 08-051. 
Otache, I., \& Mahmood, R. (2015). Corporate Entrepreneurship and Business Performance: The Role of External Environment and Organizational Culture: A Proposed Framework.

Ozdimrici, A., \& Behram, N. K., (2014). Linking Human Resources Practices to Corporate Entrepreneurship: The Mediating Role of Perceived Organizational Support. Business Management and Strategy. ISSN 2157-6068 2014, Vol. 5, No. 1. http://dx.doi.org/10.5296/bms.v5i1.4976

Phan, P. H., Wright, M., Ucbasaran, D., \& Tan, W.-L. (2009). Corporate entrepreneurship: Current research and future directions. Journal of Business Venturing, Vol. 24 (3), pp. 197-205.

Sathe, V., (1989), Fostering entrepreneurship in large diversified firm. Organizational Dynamics, 18: 20- 2.

Schmelter, R., Muer, R., Borsch, C., \& Brettel, M. (2010). Boosting corporate entrepreneurship through HRM practices: evidence from German SMEs. Human Resource Management, Wiley Inter Science. Vol. 49, No. 4, Pp. 715- 741. DOI: 10.1002/hrm.20366. www.interscience.wiley.com

Schuler, R.S. \& S.E. Jackson, (1987). Linking competitive strategies with human resource practices. Acad. Manag. Exec., 1: 207-220.

Schuler, R.S. (1986). Fostering and facilitating entrepreneurship in organizations: Implications for organization structure and human resource management practices. Hum. Res. Manag., 25(4): 607-630.

Shah, S.Z.A., \& Bhutta, N.T. (2103). Corporate Entrepreneurship and Agency Cost: A Theoretical Perspective. Open Journal of Accounting, 2, 79-86. http://dx.doi.org/10.4236/ojacct.2013.23010

Shane, S. \& Venkataraman, S. (2000). The promise of entrepreneurship as a field of research. Academy of Management Review, 25: 217-226.

Sharma, P., \& Chrisman, J.J. (1999). Towards a Reconciliation of the Definitional Issues in the Field of Corporate Entrepreneurship. Entrepreneurship Theory and Practice, 23(3), 11-27.

Soleimani, M., and Shahnazari, A., (2013). Studying Effective Factors on Corporate Entrepreneurship: Representing a Model. Research Journal of Applied Sciences, Engineering and Technology 5(4): 1309- 1316, 2013 ISSN: 2040-7459; e-ISSN: $2040-7467$.

Trott, P. (2010). Innovation Management and New Product Development. 4th Edition. Harlow, England: Prentice Hall Financial Times.

Ucbasaran, D., Westhead, P. \& Wright, M. (2001). The focus of entrepreneurial research: contextual and process issues. Entrepreneurship: Theory \& Practice, 25(4): 5780.

Wahyudi, B. (2002). Manajemen Sumber Daya Manusia.

Zahra, S. A. (1991). Predictors and financial outcomes of corporate entrepreneurship: An exploratory study. Journal of Business Venturing, 6: 259-286. 
Zahra, S. A. \& Covin, J.G. (1995). Contextual influences on the corporate entrepreneurship performance relationship: a longitudinal analysis. Journal of Business Venturing, 10: 43- 58.

Zikmund, W.G. (2003). Business research methods. Seventh edition. Thomson South Western, Mason.

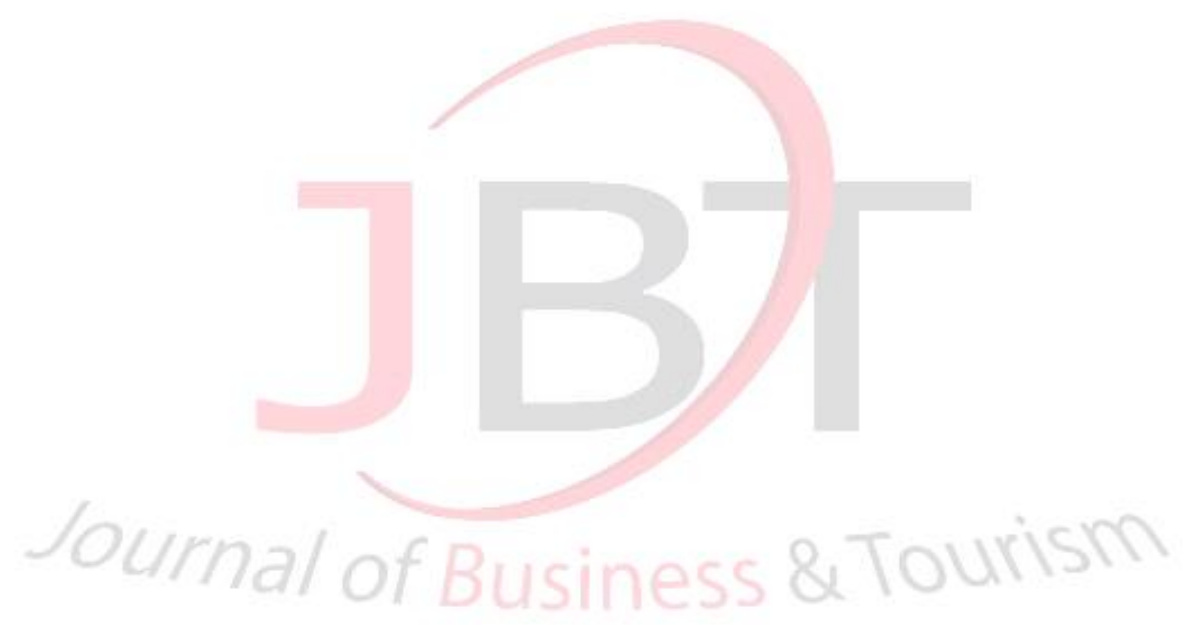

